\title{
A RELAÇÃO UNIVERSIDADE E EDUCAÇÃO BÁSICA COMO COMPROMISSO ÉTICO: OS DIÁLOGOS INTERCULTURAIS ENTRE GARRAFADAS E FÁRMACOS NA FORMAÇÃO DE PROFESSORES*
}

\author{
Danilo Seithi Kato \\ Laís de Souza Rédua \\ Glória Beatriz da Silva Honorato
}

\section{Introdução}

Gosto de dizer ainda que a escrita é para mim o movimento de dança-canto que o meu corpo não executou, é a senha pela qual eu acesso o mundo.

Conceição Evaristo

A escritora brasileira Maria da Conceição Evaristo de Brito (29 de novembro de 1946) empresta suas palavras poéticas para iniciar a discussão neste capítulo que elege a discursividade, em sua forma oral e escrita, como caminhos para pensar a superação da exclusão de corpos, sujeitos e culturas no âmbito educacional, em especial ao se tratar da formação de professores. Ao refletir sobre os processos de formação de professores do campo das Ciências da Natureza no Brasil, enquanto política pública é notável a necessidade de mudanças estruturais nos modelos de formação. A ênfase em estratégias que segregam a relação teoria e prática, pautadas em altas quantidades de carga horaria disciplinares como pressuposto de uma formação de qualidade já não se mostra convincente do ponto de vista da prática profissional (PIMENTA, 1996; GATTI, 2010)

Políticas públicas como o Programa Institucional de Bolsa de Iniciação à Docência (PIBID/CAPES), e da Residência Pedagógica vem sendo objeto de estudo de diversos pesquisadores(as) e evidenciam em seus resultados o papel dos referidos programas na criação de relações menos hierarquizadas entre teoria, tendo seu locus na Universidade, e a prática docente, com o locus na Educação Básica (SANTOS FELícIO, 2014). O Programa Institucional de Bolsa de Iniciação à Docência - PIBID, é executado

"DOI - 10.29388/978-65-86678-84-0-0-f.117-140 
por meio da Coordenação de Aperfeiçoamento de Pessoal de Nível Superior - CAPES, e tem por finalidade promover à iniciação à docência, tendo como principal meta o aumento na qualidade da educação básica pública brasileira (BRASIL, 2010). Sendo hoje uma política ameaçada pelos cortes orçamentários imprimidos pelo governo federal, notamos o retrocesso nos modelos formativos que se tornam cada vez mais distantes da possibilidade de uma reflexão mais crítica, e que considere as demandas locais no contexto de atuação docente, nomeadamente a Escola.

A partir da promulgação das Diretrizes Curriculares Nacionais para a Formação de Professores da Educação Básica há a separação entre cursos de nível Bacharelado e as Licenciaturas (BRASIL, 2002). Desta forma, o modelo disciplinar de temas e abordagens bacharelescas e focadas na transmissão dos conteúdos científicos específicos de cada área, bem como a fragmentação e isolamento das disciplinas didáticas tornam-se obsoletas e pouco eficazes na formação de um profissional que tenha que lidar com a complexidade da cultura escolar. Nas palavras de Freire (1987) a aula como uma narrativa única, se configurando como um espaço-tempo de transmitir comunicados contribui para a desumanização dos processos formativos, em outras palavras promulgam ao que o autor denominou de "cultura do silêncio".

Eliminar programas que tenham o enfoque no espaço de atuação profissional, a partir de ações de contingenciamento de recursos realizados pelo governo, e o tensionamento para reforçar um modelo de formação dual, que segrega espaços e tempos de aprendizagens, e que valoriza abordagens pouco dialógicas com a realidade de vivências dos sujeitos, se estabelece como obstáculos institucionalizados. Os quais desencontram dos parâmetros e diretrizes para uma Educação contextualizada com a cultura escolar e interdisciplinar como já indicado em documentos curriculares oficiais das esferas federais, estaduais e municipais das últimas décadas (KATO e KAWASAKI, 2011).

A formação acadêmica e a formação pedagógica parecem não dialogar como deveriam durante o processo de formação inicial de professores. E mesmo em relação às formações em serviços notamos a ausência de abordagens que revelem aspectos sociológicos, filosóficos, antropológicos, mas também conhecimentos populares e tradicionais que perfazem a realidade dos sujeitos em diferentes territórios. Neste sentido, abordagens que considerem a possibilidade de diálogos entre diferentes atores e culturas, e que, portanto, assumam a pluralidade epistêmica como 
pressuposto formativo, é tratado neste capítulo como um compromisso ético e um pressuposto teórico-prático para uma relação entre ensinopesquisa-extensão. Que articula universidade e escola de forma colaborativa com enfoque na construção de espaços e tempos que permitam a experiência em sua totalidade, e que deixe marcas e vestígios para uma possibilidade ativa de vivenciar a vida profissional docente desde seu espaço de atuação.

É preciso considerar ainda que o Brasil é um país que por suas características históricas apresenta uma grande diversidade cultural. Essa realidade pluri étnica e diversa, em um território de dimensões continentais, circunscrevem uma realidade ainda mais complexa e que possibilita um olhar mais crítico sobre os modelos de formação de professores. Os quais são pautados na estandardização de conteúdos escolares, e na homogeneização de abordagens em salas de aulas a partir de uma racionalidade tecnicista de pensar a ação docente, como já apontado em estudos anteriores (DINIZ-PEREIRA, 1999; 2014; MARANDINO, 2003)

Ainda mais se considerarmos que os documentos curriculares oficiais atuais, tais como a Base Nacional Comum Curricular (BNCC), apesar da pretensa universalidade no acesso ao conhecimento científico historicamente acumulado e flexibilizações para as realidades locais, se estabelecem como políticas mais voltadas ao controle social que a emancipação dos sujeitos (SANTOS, 2002; GALLO, 2017; FRANCO e MUNFORD, 2018). Um aspecto importante nessa ânsia de uniformizar o fazer docente a partir de carga horária, conteúdos mínimos e abordagens instrumentais, deixa de fora grande parte de minorias culturais tais como, povos do Campo, ribeirinhos, quilombolas e indígenas.

A elaboração destas políticas públicas escolares partem de uma concepção de formação que tem centro formativo (a Universidade) capacitando professores(as) para transmissão dos conhecimentos, valores e atitudes (a Escola) nos espaços oficiais, que por sua vez, tem o dever de adequar os indivíduos ao bom funcionamento social. Perspectiva que Bourdieu e Passeron (1992) discutem em sua teoria da reprodução dos sistemas da cultura dominantes por mecanismos simbólicos no âmbito escolar, e que marginalizam grande parte dos estudantes e promovendo a manutenção das desigualdades.

Assim, ao assumir o compromisso ético da relação entre Universidade e Escola creditamos aos conhecimentos tradicionais a 
materialidade discursiva que traz a realidade de vivências do sujeito para a pauta do currículo formal. Assim, partimos da seguinte questão sobre a formação do professor: Ao propor intervenções didáticas como momentos de articulação entre Comunidade e Universidade, como licenciandos do Campo percebem o diálogo da ciência com conhecimentos tradicionais? A base empírica do trabalho é construída a partir da oficina pedagógica "Entre garrafadas e fármacos: diálogos para professores de Ciências" durante a II Semana da Licenciatura em Educação do Campo - habilitação em Ciências. Assim, o objetivo da presente pesquisa é analisar como esses futuros professores de Ciências do Campo se posicionam perante situações controversas que envolvem aspectos dos saberes tradicionais de sua região e o conhecimento científico escolarizado.

\section{Por uma formação intercultural da formação de professores de ciências que integre universidade e escola}

No presente estudo analisamos uma proposta de formação de professores em uma Licenciatura em Educação do Campo, e, portanto, as potencialidades de uma formação intercultural para professores(as) em escolas do Campo. Importante salientar que o cenário de exclusão dos povos do Campo, mencionado na introdução deste capítulo, se dá principalmente por não considerar os espaços-tempos destes sujeitos que vivem fora do eixo urbano. Exclusão esta que o coloca à margem dos processos formativos, relegando a realidade e cultura destes povos. Consta na Constituição Federal defender a proteção dos conhecimentos tradicionais por meio do artigo 215, mencionando que "o Estado garantirá a todos o pleno exercício dos direitos culturais e acesso às fontes da cultura nacional, e apoiará e incentivará a valorização e a difusão das manifestações culturais" (BRASIL, 1998). Esta diversidade que ainda se vê ausente nas políticas de formação de professores para que haja a devida atenção a este direito constitucionalmente previsto.

Neste sentido, a escolha de análise da licenciatura do campo reside em sua característica fundamental quanto à pedagogia da alternância, na qual as atividades pedagógicas dividem-se entre momentos na universidade, denominados "Tempo-Escola" (TE), e em outros nas comunidades dos licenciandos, constituindo o "Tempo-Comunidade" (TC). O que permite uma proposta de mudança na relação tempo e espaço na 
trajetória de formação, implicando em uma crítica explícita à dicotomia teoria e prática impregnada nos modelos mais tecnicistas de formação. Assim a relação entre TE e TC é mais que uma divisão da carga horária em dois espaços distintos, mas uma forma de preconizar um modelo que alterna tempos e espaços sem fragmentar as experiências dos sujeitos, proporcionando a construção de situações de aprendizagens que situe os conteúdos escolares na integralidade da realidade de vivências dos sujeitos em formação (LIMA, 2012, p.49).

Contudo, é importante ressaltar que esta inovação pedagógica de inclusão, constitutiva deste curso que opera sob um regime de alternância, considera em seu cerne a interculturalidade como dispositivo, projeto, e ações, que se colocam contra a inferiorização, racialização, e qualquer silenciamento de uma episteme em detrimento de outra (WALSH, 2010). Em outras palavras, a interculturalidade não é somente uma abordagem teórica ou instrumento metodológico, é ação, práxis em um sentido Freireano. Além disso, a inclusão não pode ser vista como a assimilação ou adequação do outro aos padrões dominantes, mas sim no alargamento das zonas de circulação discursivas que considerem as distintas formas de pensamento, e que pode ser incorporada nos currículos e, portanto, na formação de professores (KATO e SANTOS, 2019, p.17).

A dificuldade em inserir na pauta escolar outros saberes justifica-se pela supervalorização científica como única fonte de saber confiável e notória, o chamado cientificismo, impondo uma organização do espaço escolar que inibe outras manifestações de saberes e desconsidera qualquer outra realidade cultural e assim se configurando como uma concepção urbanocêntrica dos processos educativos que promove o deslocamento das populações do Campo para zonas de maior vulnerabilidade socioeconômica das cidades (VENDRAMINI, 2015). Essa valorização do rigor científico como mecanismo de validação de outros saberes, é definido por Santos (2008), como "paradigma dominante" que prevalece na ciência moderna e tem como característica negar a racionalidade de outras formas de conhecimento. Pensar a ação docente para além da racionalidade técnicocientífica constitui um desafio importante para vislumbrar momentos com enfoque na tomada de consciência sobre a hegemonia do cientificismo, frente aos conhecimentos populares tradicionais, promovendo o que Santos (2007) denominou epistemicídio ${ }^{1}$.

\footnotetext{
1"Epistemicídio" é um conceito, elaborado pelo professor português Boaventura de Souza Santos, que trata da destruição de formas de conhecimento e culturas que não são
} 
De acordo com Cunha (2007), o saber tradicional e saber científico são formas de procurar entender e atuar sobre o mundo sendo estes dois saberes obras abertas, ou seja, inacabadas. No entanto, os saberes tradicionais são diferentes do saber científico. Segundo Schwartzman (1998), o conhecimento científico progride por tentativas e erros, e os conhecimentos tradicionais acumulados por um longo tempo contribuíram e contribuem para a sobrevivência de pessoas e comunidades. É importante ressaltar que o cientificismo hegemônico usa conceitos enquanto que o conhecimento tradicional usa percepções, como afirma Cunha (2007):

O conhecimento tradicional opera com as assim chamadas qualidades segundas, coisas como cheiros, cores, sabores. No conhecimento científico, em contraste, acabaram por imperar definitivamente unidades conceituais. A ciência moderna hegemônica usa conceitos, a ciência tradicional usa percepções. É a lógica do conceito em contraste com a lógica das qualidades sensíveis (CUNHA, p. 79).

As salas de aula por serem espaços multiculturais necessitam de professores sensíveis a essas diferentes visões e interpretações de mundo. Baptista (2010) discute que professores de Ciências devem prestar atenção às concepções prévias dos alunos, para planejarem as suas aulas conforme às necessidades destes estudantes e também das sociedades em que vivem. $A$ atenção às concepções prévias não tem o intuito de promover a mudança conceitual $^{2}$ em sala de aula, mas uma escuta ativa que busca o diálogo por meio das distintas culturas e atores que circulam nas aulas de ciências.

Sem esta escuta, principalmente, quando estes forem provenientes de comunidades tradicionais no qual a ciência não faz parte do cotidiano, os processos educativos serão impelidos a um grande fosso entre comunicadores, comunicados e ouvintes. É importante ressaltar que o professor ao promover o diálogo entre seus alunos ele tenha a sensibilidade para que não haja a substituição do saber tradicional pelo saber científico. Como ressalta Baptista, é necessário que haja a "[...] negociação de

assimiladas pela cultura do Ocidente branco.

${ }^{2}$ A ideia de mudança conceitual, observada nos trabalhos de Arruda; Villani (1994) e El-Hani; Bizzo (2002) é embasada no construtivismo pessoal-objetivista e se preocupa, principalmente, com a mudança de compreensões de conceitos e fenômenos de uma linguagem informal cotidiana (atribuída ao "senso comum") para aquela construída pela linguagem do conhecimento científico, validando assim a aprendizagem. 
significados culturais e de contextos de aplicabilidade de cada um dos conhecimentos envolvidos" (2018, p. 78).

Ao pensar no diálogo entre culturas que vai contra a percepção hegemônica de entender fenômenos, a perspectiva multiculturalista interativa e aberta de Candau (2011), conhecida também como interculturalidade, considera os diversos saberes existentes como mais apropriados para a construção de uma formação e consequentemente, uma sociedade inclusiva e democrática. Nesse sentido, o grande desafio dos futuros professores de Ciências é pensar os processos educativos a partir das diferenças culturais encontradas em sala de aula, valorizando o papel da alteridade e do diálogo em sua ação docente. Premissa esta que demanda também mudanças nos modelos de formação inicial de professores, em que a relação entre Universidade-Escola sejam ressignificados e as ações envolvam o entrelaçamento das ações de ensinopesquisa-extensão em prol a superação de assimetrias historicamente construídas.

Assim, é necessária uma relação entre Universidade e Educação Básica mais aproximada transformando as situações de aprendizagem em momentos de estreito diálogo com a realidade de atuação profissional. Este movimento é possível não somente por meio de programas como o PIBID e o Residência Pedagógica aqui mencionados, mas também por políticas públicas tais como O Programa de Apoio à Formação Superior em Licenciatura em Educação do Campo (PROCAMPO). Este programa apoia a implementação de cursos regulares de licenciatura em educação do campo nas instituições públicas de ensino superior de todo o país, voltados especificamente para a formação de educadores para a docência nos anos finais do ensino fundamental e ensino médio nas escolas rurais (BRASIL, 2012).

Contudo, é candente a demanda por estudos que retratem de que maneira os sujeitos do campo respondem ao modelo implementado com a política PROCAMPO em sincronia com os pressupostos da Educação do Campo que consideram a relação com os movimentos sociais de luta pela terra e pela soberania alimentar. Assim, analisar como o posicionamento dos sujeitos se manifesta frente às controvérsias mais urgentes de cada território constituem possibilidades metodológicas de mobilizar licenciandos(as) sem desconsiderar seu contexto de vida.

Mobilizações estas que se traduzam na articulação teoria-prática a partir da consideração de aspectos subjetivos e que valorizem a identidade do Campo, mas também articulem aspectos da coletividade, fundamenta- 
dos nas Ciências da Natureza, para subsidiar a tomada de posição frente aos conflitos socioambientais que regulamente compõe o cenário brasileiro e que expoliam direitos e condições de vida dos povos do Campo. Dessa forma, é possível identificar indícios de caminhos para uma formação que possibilite o acesso ao conhecimento científico e o coloque a serviço das populações marginalizadas socialmente e historicamente como um compromisso ético.

\section{Falando das garrafadas e dos fármacos: procedimentos metodológicos da investigação}

Este trabalho é caracterizado como uma pesquisa qualitativa do tipo observação participante e foi realizada a partir do desenvolvimento da oficina "Entre garrafadas e fármacos: diálogos para professores de Ciências" durante a II Semana da Licenciatura em Educação do Campo. A organização metodológica da oficina contou com a problematização de casos que expressavam situações controvérsias entre diferentes construções de pensamento e/ou de relações culturais. Os casos foram sendo colocados no decorrer da discussão da oficina como "motivo" para abordar temas incitando posicionamentos dos participantes frente a eles.

A temática analisada surge de discussões e reflexões feitas no Grupo de Estudo e Pesquisa em Interculturalidade em Educação em Ciências GEPIC com embasamento nos referenciais teóricos que problematizam as questões socioculturais, discutindo a partir das perspectivas teóricas póscoloniais e aspectos da interculturalidade na formação de professores. Por essa imersão teórica do GEPIC e com o objetivo de promover um momento de diálogo envolvendo a temática do saber tradicional e o saber científico na formação inicial de professores de Ciências, o contexto das plantas medicinais e garrafadas emergem a partir das vivências nas pesquisas desenvolvidas no grupo.

Assim, o desenvolvimento foi pensado para promover este diálogo com futuros professores do Campo que atuarão no ensino de Ciências. A proposta de uma oficina pedagógica aparece como um dispositivo importante de pesquisa, como é possível observar em Rédua (2019), por não ser encarada apenas como um marcador metodológico com finalidade de corresponder a padrões e regularidades discursivas já previstas "pedagogicamente". Mas sim por configurar a partir das situações controvérsias, mo- 
mentos de interações mediadas por diálogos tanto convergentes quanto divergentes entre diferentes culturas. Assim, o intuito foi promover espaços que, em consonância com as premissas da Pedagogia da Alternância, considerassem aspectos de interesse da Educação em Ciências em diálogo com aspectos que envolvem a realidade das comunidades, e, portanto, das escolas, em que os licenciandos(as) estão inseridos.

$O$ recorte da atividade da oficina para a análise foi referente ao Caso 01: "Se é natural não faz mal?" A oficina foi estruturada três momentos e as falas dos participantes foram gravadas em áudio. A análise dos trechos das falas que foram selecionadas buscou demonstrar a importância da formação inicial de professores de Ciências em contemplar momentos para a reflexão a partir do diálogo intercultural, tal qual permeia as relações em sala de aula. Tendo em vista essa intencionalidade, essa pesquisa apresenta como característica o contato direto com o ambiente e a situação que está sendo estudada (CORREIA, 2009; GODOY, 1995a).

Foram doze participantes pertencentes à Licenciatura em Educação do Campo - LECampo área de ciências naturais, sendo onze licenciandos e uma professora do curso. Esses membros residem em assentamentos em Rondônia, Minas Gerais nas regiões do Triângulo Mineiro e Norte de Minas. A atividade foi estruturada em três momentos, sendo o primeiro a apresentação dos participantes e da proposta da oficina pedagógica. Nesse momento, foi entregue aos integrantes um termo de consentimento para uso de imagem e depoimentos. A segunda etapa consistiu em organizar 5 grupos, os quais receberam um caso para ser discutido. A última etapa foi o

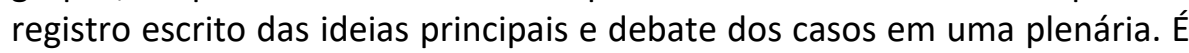
importante salientar que as considerações resultantes da argumentação foram gravadas em áudio e todos os momentos citados foram conduzidos pelos mediadores.

Tanto o tema da oficina quanto o caso escolhido derivam de uma realidade conhecida dos licenciandos, em especial na região do triângulo mineiro, da presença dos chamados "raizeiros e raizeiras" pelas ruas da cidade. São considerados como autoridades médicas e preparam as

\footnotetext{
${ }^{3}$ Raizeiros é a denominação dada aos sujeitos que mobilizam saberes da cultura popular relacionados a compreensão dos fundamentos e ações dos compostos botânicos em curas e prevenções de doenças, os quais foram construídos e validados pelas relações da cultura e transmitidos pela oralidade. Esses sujeitos representam os saberes sobre as plantas medicinais no que tange ao preparo, indicações e comercializações delas (TRESVENSOL; PAULA; RICARDO; FERREIRA; ATTA, 2006).
} 
chamadas "garrafadas" pautando-se em conhecimentos tradicionais transmitidos oralmente por parentes e antepassados. Estas misturas são preparadas de forma direcionada a cada pessoa e enfermidade e envolvem o conhecimento prático sobre as plantas da biodiversidade local, bem como seu uso contínuo passado de geração em geração. De outro lado, a relação entre Educação em Ciências e Saúde a partir de um material divulgado pelo Sistema Único de Saúde (SUS), cuja preocupação fundamental é considerar os conhecimentos tradicionais no tocante à saúde, contudo discutindo aspectos como dosagem, diluição, princípios ativos de cada planta ou parte dela utilizada nas misturas. A problematização do caso pode ser visualizada a seguir:

Figura 1: Caso elaborado com base em vivências do grupo de estudo e no curso oferecido pelo SUS sobre plantas medicinais.

Situação-problema 01: Se é natural não faz mal?
Imagine a situação: você é um professor de Ciências e quer trabalhar com seus alunos um certo
conteúdo, mas para que o assunto se torne mais atraente surge a ideia de levar para a aula o seguinte
caso:
Dona Vânia tem uma criança que não está se sentindo muito bem.... Está com a barriga inchada e
muito dolorida. Ela então lembrou da dona Aurora, uma senhora lá do bairro que conhece diversos
chás, ela nunca erra em suas receitas!
Dona Aurora disse que a menina está com lombriga e recomendou que a mãe utilizasse folhas secas
de mastruz: "Coloque as folhas secas de mastruz em um pilão e machuque-as até formar uma pasta.
Dê a vontade à criança por três dias e repita após dez dias".
Dona Vânia então seguiu a recomendação, mas no segundo dia de uso a criança começou a vomitar e
apresentou sinais de desidratação. Ela ficou preocupada e resolveu levar a menina ao médico:
- Doutor, dei para minha filha uma pasta de mastruz que a dona Aurora me ensinou a fazer.
- E quanto a senhora deu? Indagou o médico.
- Dois dias, várias vezes ao dia. Respondeu a mãe com ar de preocupação. O médico então disse:
- A dona Aurora está certa, mas creio que a senhora deu uma dose incompativel com o peso e altura
da criança.
- Mas doutor, o mastruz não é um remédio natural? Como pode fazer mal?
- A senhora pode usar fitoterápicos, eles podem ser muito benéficos a saúde, mas precisa ter cuidado
com a dose, certo? Vou lhe passar por escrito uma forma fácil para a senhora saber as doses e
medidas certas do mastruz para dar a sua criança. Logo ela estará se sentindo bem melhor.
Diante do caso, seria possivel utilizá-lo considerando que o conhecimento científico deve ser
trabalhado em sala de aula? Em caso afirmativo como seriam essas abordagens? Façam suas
considerações.

O tema da oficina surge mais precisamente durante uma aula do curso da Lecampo em que uma aluna enuncia "posso até estudar vacinas para ensinar em aulas de ciências, mas fui criada na base da garrafada e é 
nisto que acredito". O enunciado, que guarda uma contradição em si, foi mobilizado pelas(o) pesquisadoras(e) para a elaboração da intervenção no formato de oficina pedagógica no intuito de investigar o posicionamento dos(as) estudantes. Para além da validação dos conhecimentos atrelados às garrafas por parte da Ciência Moderna, o intuito foi promover uma aproximação para zonas de fronteira entre a cultura científica e a cultura popular de forma que se estabelecessem vínculos, ora por consensos, ora por dissensos.

Os posicionamentos discursivos feitos na plenária geral referente a esse caso foram utilizados como material empírico. Uma vez que utilizados para as discussões sobre as percepções dos licenciandos(as) sobre a formação a partir dos diálogos interculturais na formação de professores de ciências do Campo.

\section{O discurso, a comunidade e a escola: resultados e discussões}

Os trechos das falas selecionadas para análise partem do posicionamento dos licenciandos sobre o caso 01, para tanto analisaremos o contexto delas e como reverberam para a formação de professores e práticas de ensino da escola. A plenária inicia após a explanação do grupo sobre o conteúdo do caso e em seu decorrer evidencia algumas perspectivas principais que fundamentaram os posicionamentos.

Um primeiro licenciando socializa rapidamente a reflexão do grupo ressaltando, principalmente, a viabilidade dessa abordagem nas aulas de Ciências e aponta, ainda, que o natural pode fazer mal. Pela contradição instaurada nessa breve fala que levanta, por um lado, a proximidade do tema de plantas medicinais com o conteúdo das ciências naturais escolar, e de outro lado, pela situação dos possíveis malefícios do uso de produtos naturais, um participante que estuda a homeopatia no assentamento onde mora se posiciona:

“Parte do princípio que a diferença do remédio e do veneno é só a dosagem (momento 1) [...]Se a gente tomar um chá de ipê-roxo, garrafada feita de ipê roxo o mesmo sentido de tomar um antibiótico feito pelo ipê-roxo, vamos supor assim, mas só que o ipê-roxo está tomando diretamente o que foi extraído da planta que foi receitado para determinada coisa e a do laboratório passou por uma série de 
processos até chegar vamos supor um miligrama você consegue fazer sei lá, uma garrafada, um miligrama você consegue fazer milhares de comprimidos (momento 2)[...]" (P02).

As falas de P02 carregam duas questões principais: a primeira a importância de compreender a dosagem da mistura tendo em vista que não tem somente um lado dessa manifestação, ou seja, o impacto pode ter suas projeções benéficas e maléficas. Há nesse momento um movimento de reconhecimento e credibilidade do uso de plantas medicinais bem como o comprometimento deste conhecimento para seu uso por conta dos possíveis efeitos.

Em segundo, é interessante perceber a exemplificação do ipê-roxo e o antibiótico configurando a relação do conhecimento da medicina ocidental e medicina popular. À vista desse posicionamento paira a colocação de diferentes estruturas de pensamentos sobre saberes tradicionais como as dosagens para as garrafadas e dosagens de comprimidos da indústria farmacêutica representando a ciência. Considerando a ênfase em apresentar duas referências de conhecimento durante um momento formalizado na e pelas ações da Universidade, esse início já demonstra que as intenções da oficina pedagógica afetaram algumas lacunas sobre as formas de conhecer que são suprimidas, assim como seus formatos inteligíveis. Por tocar nessas narrativas silenciadas, o andamento da oficina convergiu para o que Baptista (2010, p.687) discute sobre ser "preciso criar situações para que os estudantes percebam como a prática da ciência pode se beneficiar dos achados de outros domínios de conhecimento".

Vale aqui a ressalva que historicamente a Universidade está inscrita como local da busca e formalização de "regimes de verdades", palavras de Foucault, provenientes das opacidades e silêncios das produções culturais gerados pela ciência moderna (SANTOS, 2002). Logo, tais silêncios como a do conhecimento ancestral de comunidades tradicionais começam nesse momento a aparecer como outro formato de construção, mas que gera certa polarização. Isto ocorre pela própria fundamentação de validade do conhecimento. $O$ conhecimento tradicional acontece por evidências, assim como o da ciência moderna, no entanto, essas são observadas e passadas geralmente de forma oral ao longo das gerações. Tem suas bases e percepções que se fortalecem ao longo de tempo e que não possuem um catálogo pronto a ser acessado justamente por essa dinamicidade das 
percepções (CUNHA, 2007). Diferente da ciência moderna, e aqui representada na medicina ocidental, em que as dosagens são estipuladas, constatadas por tentativa e erro ao longo do tempo e padronizadas para o consumo na forma de comprimidos ou líquidos, respeitando um regime de comprovação de fatos.

A forma com que essas construções de conhecimentos são firmadas nas relações socioculturais ainda foi reafirmada em outro momento da plenária e em seguida a localização hierárquica com que se configuram nas relações também é manifestada.

\begin{abstract}
"[...] o que acontecia antigamente era baseado em evidências e às vezes o que aconteceu ali foi a evidência de um efeito colateral que poderia passar em pouco tempo" (P03).

"O que é pregado para a pessoa é isso: você está ruim vai ter que ir ao médico, será que o médico é o cara mais indicado? Porque ela não foi na senhora da erva? [...] Isso dá para você fazer a controvérsia dos fatos" (P04).
\end{abstract}

A polarização evidente que tensiona as diferentes dimensões, como elas se projetam e são creditadas socialmente é o marco do segundo momento da plenária, que ganha um crescente nas interações após o início da discussão sobre a importância da medicina popular pelo uso de plantas medicinais. É acentuado o posicionamento empregando duas construções epistêmicas, as quais são tensionadas nos questionamentos a partir de suas aproximações e distanciamentos. A abordagem e questionamentos que aparecem pela problematização inicial se desdobra no que Baptista (2010; 2018) chama de pluralidade epistêmica. O eco de discurso que orienta o posicionamento ocorre pela construção e confiabilidade máxima concedida à ciência moderna que opera socialmente pelo discurso cientificista de sua posição. A colocação da ciência moderna e suas teorias como o suprassumo para compreender todos os aspectos da vida e de fenômenos (BAPTISTA, 2014).

Olhando para os discursos a pluralidade vai se construindo, ainda que não seja pela consciência plena dos sujeitos diante da superação de uma epistemologia dominante para essas multiplicidades. A contribuição de P03 na discussão traça além dos indícios, a relação de como isso se projeta nas demais gerações. Há a relação técnica em que as evidências do conhecimento tradicional são traduzidas nas ações coletivas em relação à 
saúde do grupo. Todavia, essa técnica não corresponde ao discurso produzido pelos desígnios políticos e ideológicos da racionalidade científica e suas bases teóricas, que segundo Boaventura Sousa Santos

\begin{abstract}
Assentam no pressuposto de que o conhecimento é válido independente das condições que o tornaram possível. Por isso, a sua aplicação independe igualmente de todas as condições que não sejam necessárias para garantir a operacionalidade técnica da aplicação. Tal operacionalidade é construída através de um processo que designo por falsa equivalência de escalas e que consiste em produzir e ocultar um desequilíbrio de escala entre ação técnica e consequências técnicas (2002, p.31).
\end{abstract}

O autor diz ainda que é por meio desse desequilíbrio e falsa equivalência que esse paradigma se dá que gera um heroísmo técnico do cientista. Não se pode negar a importância das técnicas científicas para promoção de conhecimento, no entanto, a contradição está circunscrita na forma com que a técnica se arquiteta de maneira absoluta para construção de conhecimento pela descontextualização desta equivalência entre ação e consequência de sua técnica (SANTOS, 2002). Essa descontextualização ainda possibilitou o modelo de profissionalização que domina atualmente pela racionalidade técnica (DINIZ-PEREIRA, 1999), ao mesmo tempo temos também discussões atuais que se projeta em um coro de críticas sobre ela (DINIZ-PEREIRA, 2014; BAPTISTA, 2010; 2014; 2018; RÉDUA, 2019). Contudo, a base da racionalidade técnica no modelo de aprendizagem na educação e a relação técnica pela historicidade de práticas que contribuem com o coletivo frente ao contexto das plantas medicinais possuem diferentes sentidos e validades socialmente.

Algumas extrapolações teóricas foram feitas para delimitar a conjuntura pela qual os enunciados se formalizam e como os diferentes sentidos se conformam, por exemplo, pela natureza "técnica" dessas construções. A inferida pluralidade epistemológica quando aparece como ponto de partida significa um exercício reflexivo inicial acerca da hierarquia cientificista que considera apenas uma única técnica como válida instaurada nos processos educativos, a qual anula o diálogo com diferentes epistemologias. Essa concepção reproduzida nas gerações, que além de hierarquizar, impossibilita a relação de interconhecimento, dicotomiza o acesso e compreensão entre um ou outro e nunca uma negociação de ambos (SANTOS, 2007). 
A situação da oficina pedagógica oportunizou olhar esses diferentes contextos em que os discursos sobre o mesmo tema se constroem pelas manifestações e posicionamentos ligados a práticas cotidianas dos sujeitos. Quando o licenciando delimita a diferença e proximidades entre a garrafada e a produção do comprimido problematizam a personificação da autoridade médica por argumentos que remetem suas questões identitárias e realidade sociocultural. Diante disso, percebe-se que o P04, por exemplo, questiona a procura imediata do médico em vez de buscar o conhecimento popular sobre as ervas, dando, portanto, relevância à "controvérsia dos fatos" como caminho para se estabelecer uma discussão em sala de aula.

Pela forma com que os licenciandos transitam na relação espaçotempo pelo discurso que potencialmente valoriza a cultura popular tradicional e o polariza do discurso da ciência, foi questionado na plenária como isso se configura no ensino da ciência escolar. Visto que esses licenciandos do Campo estão em formação para atuar nas áreas das Ciências da Natureza. O participante P02 relata como aborda em suas práticas:

\begin{abstract}
"Dependendo da idade dos alunos que entendesse isso porque de certa forma eu costumo assemelhar isso muito com a homeopatia. A homeopatia trabalha com esse sentido do saber popular, do chá. De certa forma, você consegue na realidade minha, no contexto que eu vivo você consegue conversar com as crianças a respeito disso, porque lá isso é bem comum entre as famílias" (P02).
\end{abstract}

Internalizando a posição hegemônica do conhecimento científico bem como refletir maneiras de desestabilizar essa forma incisiva de determinar as verdades é um ponto que não foi negado durante a discussão. Por essa tomada de consciência não significa, por outro lado, que seja necessário um esvaziamento da ciência e da importância de seus feitos para a sociedade. Quando P02 aborda o conversar não fica explícito sobre como a compreensão da ciência nas relações existenciais dos sujeitos como forma de estreitar laços aprofundando na epistemologia das ciências e do conhecimento tradicional para alargamento das zonas de circulação discursiva (KATO e SANTOS, 2019). Para tanto, posicionamentos discursivos com a alternância de tempos e espaços que carregam em si as memórias e experiências frente aos aspectos da formação docente contribuem para um repensar em busca da superação dos modelos de racionalidade técnica que 
segregam teoria e prática. Por isso as práticas na universidade precisam explorar essa consciência, para não cair na negação nem da ciência nem da produção ancestral, proposta em que a Pedagogia da Alternância tem como horizonte para pensar uma formação presencial em diferentes temposespaços articulando diferentes construções epistemológicas para constituição do futuro docente.

O terceiro momento da discussão foi uma terceira análise de P03, que ocorre após os posicionamentos e a mediação acerca deles sobre as tensões da polarização dos conhecimentos frente aos processos educativos e da formação docente.

\begin{abstract}
“[...] mas vendo que talvez não estava fazendo efeito ela procurou um médico e talvez discutir essa importância da ciência. Porque ela foi procurar um médico? O peso da autoridade do médico ali é muito forte. E o mais interessante do caso é que o médico ele não foi para a linha do fármaco industrializado, ele foi para a linha da senhora, então ali eu enxergo de fato um diálogo [...]" (P03).
\end{abstract}

Até o momento, pela dicotomia estabelecida, houve uma polarização para a construção tradicional, mas que minimizou a ciência nesse diálogo. Levando, possivelmente, outro formato de sobreposição dos conhecimentos, de forma que não é o intuito quando se pensa a formação de professores sensíveis às contradições socioculturais e a crítica aos modelos educativos. Sendo assim, nesse último ponto de posicionamento há outra perspectiva, que olha para a figura do médico, historicamente detentor do saber da medicina ocidental, com postura que não está fixa nesse tradicionalismo hegemônico. E ainda, há um início de mobilização que pega desse sentido para buscar a discussão da importância da ciência na situação em que, acessando ambas as visões, houve então a tomada de decisão. Nesse caso, o saber tradicional pelas plantas medicinais foi o caminho escolhido para o tratamento.

Em suma, por esses pontos é possível visualizar pela construção dos discursos e o pensar sobre modalidades de ensinar de maneira que não sejam apenas reafirmando uma relação hegemônica das plantas medicinais como um complemento do ensino de ciências na incessante busca da "achegar o conteúdo do cotidiano" de maneira abstrata. Todavia, partir da contradição e conceber os dissensos e consensos dela com a construção discursiva posta e reiterada socialmente para que sejam acessados pontos 
de sutura que dialogue com a ancestralidade, a ciência e a formação do sujeito num alargamento de suas visões de mundo (WALSH, 2010). Ainda que não tenha sido numa intencional consciência, a própria estrutura da oficina que tensiona pelo que é controverso, causa um distúrbio mesmo que incipiente nos posicionamentos. De modo que não seja dado pela reafirmação de um ou outro, hierarquizando ou subalternizando, mas, na busca do diálogo e negociação de construções culturais distintas (BAPTISTA, 2014).

\section{A interculturalidade e o compromisso ético: considerações finais}

Em acordo com o objetivo proposto, foi realizada a análise de como os futuros professores de Ciências se posicionam perante situações controversas no espaço formativo. O movimento dos discursos e posicionamentos partiu da reafirmação do uso da medicina tradicional, por meio do conhecimento das plantas medicinais, que levou a colocações sobre as diferentes produções, utilização e credibilidade dos conhecimentos na sociedade e na escola. Esse percurso no primeiro e segundo momento principal da discussão polariza as construções de conhecimentos gerados em diferentes tempos-espaços, tais como foram destacados o conhecimento científico e o conhecimento popular de comunidades tradicionais.

Pela tensão da polarização a mediação buscou tocar em questões ainda mais controversas, para que a sobreposição entre um ou outro conhecimento não fosse dada como fim da discussão, mas que por suas diferenças fossem pensados como a pluralidade poderia ser pauta na educação básica, assim como estava na formação docente. Nesse sentido, deságua num momento final da plenária na reflexão, ainda embrionária, pela não fixação dos sujeitos e construções discursivas como dadas, tendo o exemplo do médico como aquela que enuncia pela medicina ocidental sem pensar outros métodos benéficos para promoção de saúde.

Afinal, o uso do Ipê-roxo, e a efetividade dos compostos químicos desta planta para determinada enfermidade, não foram questionados. O debate se dá inicialmente pela relação da dosagem e da padronização de um produto a ser comercializado. Essa discussão mostrou-se campo fértil para a valorização da pluralidade epistêmica. Por tais mobilizações iniciais foi possível pensar sobre o diálogo e negociação dos saberes como 
constitutivo do ensinar e aprender ciências da natureza, não apenas pela objetificação dos fenômenos pela lente cientificista, mas por colocar esses fenômenos por diferentes olhares.

Reverbera assim na relação das práticas na universidade para seu compromisso ético pela diferença cultural, mobilizando pela formação de professores, e suas influências atuais e futuras na educação básica para que sejam sensíveis às questões socioculturais que ressaltam elementos identitários desse sujeito de sua rede cultural e não só dentro de uma conformação profissional de pensar como o professor. Ao encarar a conjuntura de uma educação urbanocêntrica e os silêncios das práticas e conhecimentos ancestrais produzidos por ela, é importante que os conhecimentos tradicionais estejam na pauta do processo formativo de professores de Ciências, para que isso possa ressoar na sociedade. Assim, explorando do sentido da Pedagogia da Alternância para incitar a educação pela problematização e controvérsia assume um repensar sobre as identidades de forma que o sujeito seja considerado a partir da valorização de suas raízes culturais.

\section{Referências}

ARRUDA, S. M.; VILLANI, A. Mudança conceitual no Ensino de Ciências.

Caderno Catarinense de Ensino de Física, 11(2): 88-99. 1994.

\section{BAPTISTA, G, C, S. A contribuição da etnobiologia para o ensino e a} aprendizagem de ciências: estudo de caso em uma escola pública do estado da Bahia. Salvador: 2007. 180 f. Dissertação (Mestrado) Universidade Federal da Bahia: Universidade Estadual de Feira de Santana, Salvador, 2007. Disponível em: https://repositorio.ufba.br/ri/bitstream/ri/15805 /1/Geilsa\%20Costa\%20Santos\%20Baptista.pdf. Acesso em: 17 abr. 2020.

BAPTISTA, G. C. S. Importância da demarcação de saberes no ensino de Ciências para sociedades tradicionais. Ciência \& Educação, v. 16, n. 3, 2010, p. 679-694. Disponível em: http://www.scielo.br/pdf/ciedu/v16n3/v16n3a12.pdf. Acesso em: 16 abr. 2020. 
BAPTISTA, G. C. S. Do cientificismo ao diálogo intercultural na formação do professor e ensino de ciências. INTERACÇõES. n. 31, p. 28-53, 2014. Disponível em: https://revistas.rcaap.pt/interaccoes/article/view/6369. Acesso em: 16 abr. 2020.

BAPTISTA, G, C, S.; Araujo, G. M. Práticas etnobiológicas para o desenvolvimento da competência intercultural na formação do professor de biologia. GAIA SCIENTIA. v. 12 n. 2, p.76-88, 2018. Disponível em: https://www.researchgate.net/publication/325985393_Praticas_etnobiolog icas_Para_o_desenvolvimento_da_comPetencia_intercultural_na_formaca o_do_Professor_de_biologia. Acesso em: 17 abr. 2020.

BRASIL. Constituição. Constituição da República Federativa do Brasil. Brasília, DF: Senado Federal, 1998. Disponível em:

http://www.planalto.gov.br/ccivil_03/Constituicao/Constituicao.htm. Acesso em: 28 abr. 2020.

BRASIL. Ministério da Educação. Conselho Nacional de Educação. Parecer CNE/CP 009/2001. Diretrizes Curriculares Nacionais para a Formação de Professores da Educação Básica, em nível superior, curso de licenciatura, de graduação plena. Diário Oficial da União, Brasília, DF, 18 jan. 2002. Seção 1, p. 31.

BRASIL. Decreto n. 7.219, de 24 de junho de 2010. Dispõe sobre o Programa Institucional de Bolsa de Iniciação à Docência - PIBID e dá outras providências. Diário Oficial da União, Poder Executivo, Brasília, DF, 26 jun. 2010. Seção 1, p. 4

BRASIL. MEC. Programa Nacional de Educação do Campo: PRONACAMPO. Brasília/ DF: MEC, Março de 2012. Disponível em http://www.consed.org.br/images/phocadownload/pronacampo.pdf. Acesso em 31 mar. 2020.

BOURDIEU, P.; PASSERON, J.-C. A reprodução. 3.ed. Rio de Janeiro: Francisco Alves, 1992. 
CANDAU, V. M. Diferenças culturais, cotidiano escolar e práticas pedagógicas. Currículo sem Fronteiras, v. 11, n. 2, p. 240-255, 2011. Disponível em: http://www.curriculo semfronteiras.org/vol11iss2articles/candau.pdf. Acesso em: 17 abr. 2020

CORREIA, M. C. B. A observação participante enquanto técnica de investigação. Pensar Enfermagem, Lisboa (Portugal): Escola Superior de Saúde do Instituto Politécnico de Beja. v. 13, n. 2, 2009. Disponível em: http://pensarenfermagem.esel.pt/files/2009_13_2_30-36.pdf. Acesso em: 17 abr. 2020

CUNHA, M. C. Relações e dissensões entre saberes tradicionais e saber científico. Conferência realizada na Reunião da SBPC em Belém, Pará, em 12/7/2007. Disponível em:

http://www.revistas.usp.br/revusp/article/view/13623. Acesso em: 17 abr. 2020

DINIZ-PEREIRA, J. E. Licenciaturas e as novas políticas educacionais para a formação docente. Educação e Sociedade, v. 20, n. 68 - Especial, p. 109125, dez. 1999.

DINIZ-PEREIRA, J. E. Da racionalidade técnica a racionalidade crítica: formação docente e transformação social. Perspectivas em Diálogo: Revista de Educação e Sociedade, v. 01, n. 01, p.34-42, 2014.

EL-HANI, C. N; BIZZO, N. M. V. Formas de Construtivismo: Mudança Conceitual e Construtivismo Contextual. Ens. Pesqui. Educ. Ciênc. (Belo Horizonte) [online]. vol.4, n.1, pp.40-64. 2002.

FRANCO, L. G.; MUNFORD, D. Reflexões sobre a Base Nacional Comum Curricular: Um olhar da área de Ciências da Natureza. Horizontes, v. 36, n. 1, p. 158-170, jan./abr. 2018.

FREIRE, P. Pedagogia do Oprimido. Rio de Janeiro: Paz e Terra, 1987.

GALLO, S. Base Comum Curricular, um instrumento da biopolítica. Revista do Instituto Humanitas Unisinos, n.516, ano XVII, dezembro de 2017, p.3741. 
GATTI, B. A. Formação de Professores no Brasil: características e problemas. Educ. Soc., Campinas, v. 31, n. 113, p.1355-1379. 2010.

GODOY, A. S. Pesquisa Qualitativa Tipos Fundamentais. Revista de Administração de Empresas. São Paulo, v. 35, n. 3, p. 20-29, 1995. Disponível em: http://www.scielo.br/pdf/rae/v35n3/a04v35n3.pdf. Acesso em 11 set. 2018.

KATO, D. S.; KAWASAKI, C. S. As concepções de contextualização do ensino em documentos curriculares oficiais e de professores de ciências. Ciênc. educ., Bauru, v. 17, n. 1, p. 35-50, 2011. Disponível em http://www.scielo.br/scielo.php? script=sci_arttext\&pid=S151673132011000100003\&lng=en\&nrm=iso. Acesso em 31 mar. 2020.

KATO, D. S.; SANTOS, A. A. P. P. "Cadê a puba?": por uma formação intercultural de professores de biologia em uma comunidade amazônica. Revista Multidisciplinar em Educação, Porto Velho, v. 6, n 16, p. 344-363, out/dez., 2019.

LIMA, A. V. Educação do campo e pedagogia da alternância: algumas considerações metodológicas. Entrelaçando - Revista Eletrônica de Culturas e Educação, v. 2, n.6, p. 46-60, set.-dez. 2012. Disponível em: https://www2.ufrb.edu.br/revistaentrelacando/component/phocadownloa d/category/186-? Itemid=0 Acesso em: 17 abr. 2020

MARANDINO, M. A Prática de Ensino nas Licenciaturas e a Pesquisa em Ensino de Ciências: questões atuais. Caderno Brasileiro de Ensino de Física, Florianópolis, v. 20, n. 2, p. 168-193, 2003.

MORTIMER, E. F.; EL-HANI, C. N. Conceptual Profiles: A Theory of Teaching and Learning Scientific Concepts. Series: Contemporary Trends and Issues in Science Education. Springer: v. 42, 330 p. 2014.

PIMENTA, S. G. Formação de professores: saberes da docência e identidade do professor. Revista da Faculdade de Educação da USP, São Paulo. v. 22, n. 2, p. 72-89. jul/dez 1996. 
RÉDUA, L. de S. Interculturalidade crítica na formação inicial de professores de ciências: Saberes sobre a biodiversidade local. Dissertação (Mestrado em Educação) - Universidade Federal do Triângulo Mineiro. Uberaba. 101p. 2019.

SANTOS, B. S. Crítica da razão indolente: contra o desperdício da experiência. Porto: Edições Afrontamento. 2002.

SANTOS, B. S. "Para além do Pensamento Abissal: Das linhas globais a uma ecologia de saberes". Revista Crítica de Ciências Sociais, 78, 3-46. 2007.

SANTOS, B. S. Um discurso sobre as ciências. 5. ed. São Paulo: Ed. Cortez, 2008. 93 p.

SANTOS FELÍCIO, H. M. O PIBID como "terceiro espaço" de formação inicial de professores. Revista Diálogo Educacional, vol. 14, núm. 42, mayoagosto, 2014, pp. 415-434 Pontifícia Universidade Católica do Paraná Paraná, Brasil. Disponível em:

https://www.redalyc.org/pdf/1891/189131701006.pdf. Acesso em 28 abr. 2020

SCHWARTZMAN, S. Saberes cientificos e saberes populares. In: REUNIÃO ANUAL DA ASSOCIAÇÃO BRASILEIRA DE ANTROPOLOGIA, 1998, Vitória, Anais..., Vitória, abril de 1998. Disponível em:

http://www.schwartzman.org.br/simon/ABA.htm. Acesso em: 19 set. 2018.

TRESVENZOL, L. M., PAULA, J. R., RICARDO, A. F., FERREIRA, H. D., ATTA, D. T. Estudo sobre o comércio informal de plantas medicinais em Goiânia e cidades vizinhas. Revista Eletrônica de Farmácia, 3(1): 23-28. 2006.

VENDRAMINI, C. R. QUAL O FUTURO DAS ESCOLAS NO CAMPO? Educ. rev., Belo Horizonte, v.31, n.3, p.49-69, Sept. 2015. Disponível em: https://www.scielo.br/pdf/edur/v31n3/1982-6621-edur-31-03-00049.pdf. Acesso em 28 abr. 2020.

WALSH, C. Estudios (inter)culturalesen clave decolonial. Tabula Rasa, n. 12, p. 209-277, 2010. 